\title{
TEKNIK PENGUMPULAN DATA SAMPEL TUMBUHAN UNTUK PEMBUATAN SPESIMEN HERBARIUM
}

\author{
${ }^{1}$ Rizki Rizki \& ${ }^{2}$ Des M \\ ${ }^{1}$ Program Studi Budi Daya Tanaman Hortikultura Politeknik Pertanian Negeri Payakumbuh \\ ${ }^{2}$ Jurusan Biologi Universitas Negeri Padang \\ Corresponding Author: \\ khi_bio@yahoo.com
}

\begin{abstract}
ABSTRAK
Kekayaan vegetasi yang sangat tinggi dapat terdokumentasikan dengan baik dengan pembuatan spesimen herbarium. Herbarium merupakan bagian tumbuhan yang sudah diawetkan dengan teknik-teknik tertentu, diberi label identitas dan umumnya digunakan untuk keperluan ilmiah. Herbarium juga disebut juga dengan gedung atau tempat dimana spesimen itu disimpan. Pembuatan herbarium melewati beberapa tahapan mulai dari pengambilan spesimen kelapangan, pengawetan sementara dilapangan, pengeringan, mounting dan penyimpanan spesimen. Pembuatan spesimen herbarium ini bertujuan untu mendokumentasikan kekeyaaan tumbuhan. Sedangkan manfaatnya dapat digunakan untuk penelitian dan bahan pembelajaran baik di sekolah menengah maupun di perguruan tinggi
\end{abstract}

Key Word: Awetan, Herbarium, Spesimen, Tumbuhan

\section{PENDAHULUAN}

Indonesia memiliki tingkat keanekaragaman vegetasi yang sangat tinggi, untuk itu perlu suatu cara mendokumentasikan kekayaan alam tersebut, salah satunya dengan melakukan pengewatan terhadap tumbuhan untuk dibuat menjadi spesimen atau herbarium. Untuk mendapatkan awetan yang bermutu dan berkualitas perlu teknik yang benar dalam melakukan pengawetan. jika proses pengawetan ini tidak tepat maka akan menyebabkan spesimen berkerut/keriting, rapuh, mudah berjamur dan akibatnya spesimen tidak dapat bertahan lama.

Keberhasilan mempelajari taksonomi tumbuhan dapat dicapai dengan baik salah satunya adalah memanfaatkan specimen herbarium yang baik. Untuk menghasilkan herbarium yang baik harus dimulai dengan koleksi yang baik pula. Penyiapan koleksi yang lengkap, baik dan sempurna adalah aspek yang sangat penting bagi suatu specimen yang baik, sehingga dapat digunakan untuk material studi taksonomi tumbuhan. 


\section{PEMBAHASAN}

\section{Tujuan Pembuatan Spesimen Herbarium}

a. Mendokumentasikan kekayaan flora yang sangat tinggi

b. Menggambarkan karakteristik species tumbuhan yang diawetkan

c. Mengetahui bentuk-bentuk morfologi tumbuhan tingkat tinggi (daun, batang, bunga, buah dan biji) yang menjadi ciri khas suatu tumbuhan

\section{Manfaat Pembautan Herbarium}
a. sebagai spesimen yang akan menjadi acuan untuk publikasi spesimen baru
b. sebagai bahan untuk melihat adanya variasi morfologi
c. dapat digunakan untuk menyusun kunci determinasi tumbuhan
d. untuk alat bantu dalam melakukan identifikasi tumbuhan
e. alat bantu identifikassi dalam mempelajari etnobotani baik etnobotani tumbuhan obat- obatan (Leilani, Rizki, Sari \& Sari, 2017), identifikasi spesimen dalam etnobotani pemanfaatan tumbuhan untuk upacara adat (Des, Rizki \& Hidayati, 2018)
f. sebagai media yang dapat digunakan untuk penelitian
g. dapat dijadikan sebagai pertukaran spesimen antar negara
h. dapat digunakan sebagai alat peraga disekolah menengah maupun perguruan tinggi
i. untuk pemuliaan tanaman dapat dijadikan acuan untuk pengembangan spesies baru

\section{Alat dan Bahan}
a. Gunting tanaman
b. Koran bekas yang sudah di potong dua
c. Karung beras
d. Plastik ukuran karung (atau $50 \mathrm{~kg}$ )
e. Pisau cutter
f. Tali rafia
g. Label gantung (ukuran $3 \mathrm{~cm} \times 3 \mathrm{~cm}$ yang diikat dengan benang "jagung” $30 \mathrm{~cm}$ )
h. Triplek ukuran maksimal 30x40 (jika diperlukan)
i. Pensil, Spidol permanent, Buku dan alat tulis
j. Alkohol $96 \%$ atau alkohol 70\%, spritus (sebaiknya alkohol 96\%)
k. FAA (untuk awetan basah)
1. Kertas monting (tidak dibawa ke lapangan) 
m. Kertas Kalkir (tidak dibawa ke lapangan)

\section{Cara Kerja}

\section{Di lapangan}

a. Amati tumbuh-tumbuhan yang ada di lapangan

b. Sampel diambil di lapangan rangkap tiga (kalau tumbuhannya sedikit ambil dua sampel saja atau satu saja)

c. Sampel diberi label gantung atau label lapangan yang telah di tulis nomor koleksinya

d. Catat tempat hidup tumbuhan, habitus (perawakan batang) warna daun, pucuk (daun muda atau daun tua), bunga, buah dan biji (jika ada), bau, rasa dan ciri-ciri khas lainnya, catatan disesuai dengan nomor koleksi yang diberi pada sampel dengan label gantung. (catat pada lembaran yang telah disediakan) sebaiknya satu rangkap tidak diawetkan, untuk identifikasi sementara (Rugayah, Windadri, \& Hidayat. 2004)

e. Masukan ke dalam karung dengan diatur serapi mungkin. Meletakkan sampel dalam karung harus di rebahkan. (sampel yang diambil harus lengkap ranting, daun dan bunganya) ukuran sampel yang diambil tidak lebih dari $30 \mathrm{~cm}$. Jika tinggi tumbuhan tidak lebih dari $30 \mathrm{~cm}$ harus diambil sampai akarnya (Des, 2007), kalau tumbuhan itu parasit maka tumbuhan inang tempat tumbuhnya harus terbawa, contoh benalu yang tumbuh di ranting jengkol, maka ranting jengkol tempat tumbuh melekatnya benalu tersebut juga di koleksi (Rizki, 2011)

f. Kemudian sampel dalam karung dibawa ke posko (sementara) tempat yang dijadikan untuk pengepakan awal tumbuhan.

g. Sampel disusun di atas kertas koran serapi mungkin, masing-masing koran hanya terdapat satu sampel

h. Sampel disusun dan ditumpuk dengan rapi, jangan sampai ada bagian tumbuhan yang keluar lipatan kertas koran, satu atau dua helai daun harus telentangkan sehingga terlihat bagian bawah daunnya

i. Setelah semua sampel tanaman tersusun dengan rapi kemudian ikat dengan tali rafia, jangan mengikat terlalu keras.

j. Masukan ke dalam kantong plastik dan diberi alkohol 96\%, atau jika tidak ada boleh menggunakan alkohol $70 \%$ atau spritus secukupnya (jika menggunakan spritus sampel yang telah disiram harus secepatnya dikeringkan, maksimal satu hari.

k. Tutup plastik dengan rapat, jangan sampai menyisakan rongga udara 
1. Rekatkan dengan lakban mulut plastiknya, jangan sampai ada udara yang masuk (hanya mulut plastik saja)

m. Koleksi sampel sudah boleh dibawa pulang atau ke laboratorium

n. Agar lebih aman dan jangan terlipat bagian atas dan bawahnya diberi dengan triplek atau kardus terbal dengan ukuran yang sama $(30 \times 40)$

o. Ikat kuat dengan tali rafia

\section{Di laboratorium}

a. Sampel dikeluarkan dari plastiknya, dan jika belum tersusun rapi, buka ikatan tali rafia tadi dan susun kembali

b. Ukuran sampel tumbuhan sebaiknya $30 \mathrm{~cm}$, dan jika panjang harus dibelokkan atau jika memungkinkan dipotong saja

c. Kemudian susun kembali sampel di atas kertas koran serapi mungkin, masing-masing koran hanya terdapat satu sampel

d. Sampel dituumpuk masing-masing 5 sampel dalam kertas koran, setiap 5 sampel harus dibatasi dengan 1 lebar kardus agar sirkulasi panas saat pengeringan terjaga

e. Bagian atas dan bawah tumpukan sampel diberi kardus tebal atau triplek, atau jika ada gunakan besi plat, kemudian ikat kuat dengan tali rafia, namun lebih baik gunakan tali jemuran (sampel harus terus di tekan kuat agar tidak keriting)

f. Sampel dikeringkan dengan oven dengan suhu $75^{\circ} \mathrm{C}$ selama 2 hari, atau langsung dengan penjemuran dengan sinar matahari, sekitar 1 minggu, sampel jangan sampai terkena air.

g. Setelah sampel benar-benar kering, kemudian dijahitkan di atas kertas monting dengan ukuran maksimal 30x40 (ukuran jangan sampai berlebih)

h. Kemudian beri label herbarium (label ditempel di sebelah kiri herbarium)

i. Herbarium di fotocopy untuk mendapatkan bentuk morfologi dasar dari tumbuhan

j. Spesimen yang didapatkan harus digambar di atas kertas kalkir

k. Sesuikan deskripsi dengan buku catatan yang anda tulis di lapangan

1. Kemudian buat satu buah map herbarium dari karton tebal.

m. Herbarium yang telah dibuat dimasukan ke dalam map herbarium tersebut 


\section{Cara Pengisian Label Herbarium}

Family : Familia tumbuhan yang diherbariumkan

Species : Nama latin spesies yang diherbariumkan

Det. : Nama Orang (anda atau teman anda) yang mengklasifikasikan tumbuhan tersebut

Date $\quad$ : Waktu (Tanggal/bulan/tahun) mengklasifikasikan tumbuhan

Locality : tempat atau lokasi tempat pengambilan sampel

Coll : Nama kolektor atau orang yang mengkoleksi tumbuhan ini

No. Coll : Nomor koleksi

Det. $\quad$ : tanggal melakukan pengambilan sampel

Habitat $\quad$ : tempat hidup tumbuhan (hidrofit, mesofit, xerofit, epifit dll)

Vern Name : Nama daeran tumbuhan yang dikoleksi

Annote : catatan penting tumbuhan (bagian-bagian yang tidak terlihat setelah tumbuhan di buat herbarium, habitus, habitat, warna bunga, warna pucuk atau daun muda, warna daun tua, bau, rasa, dan karakteristik lainnya yang tidak dapat diamati pada herbarium yang sudah kering) 


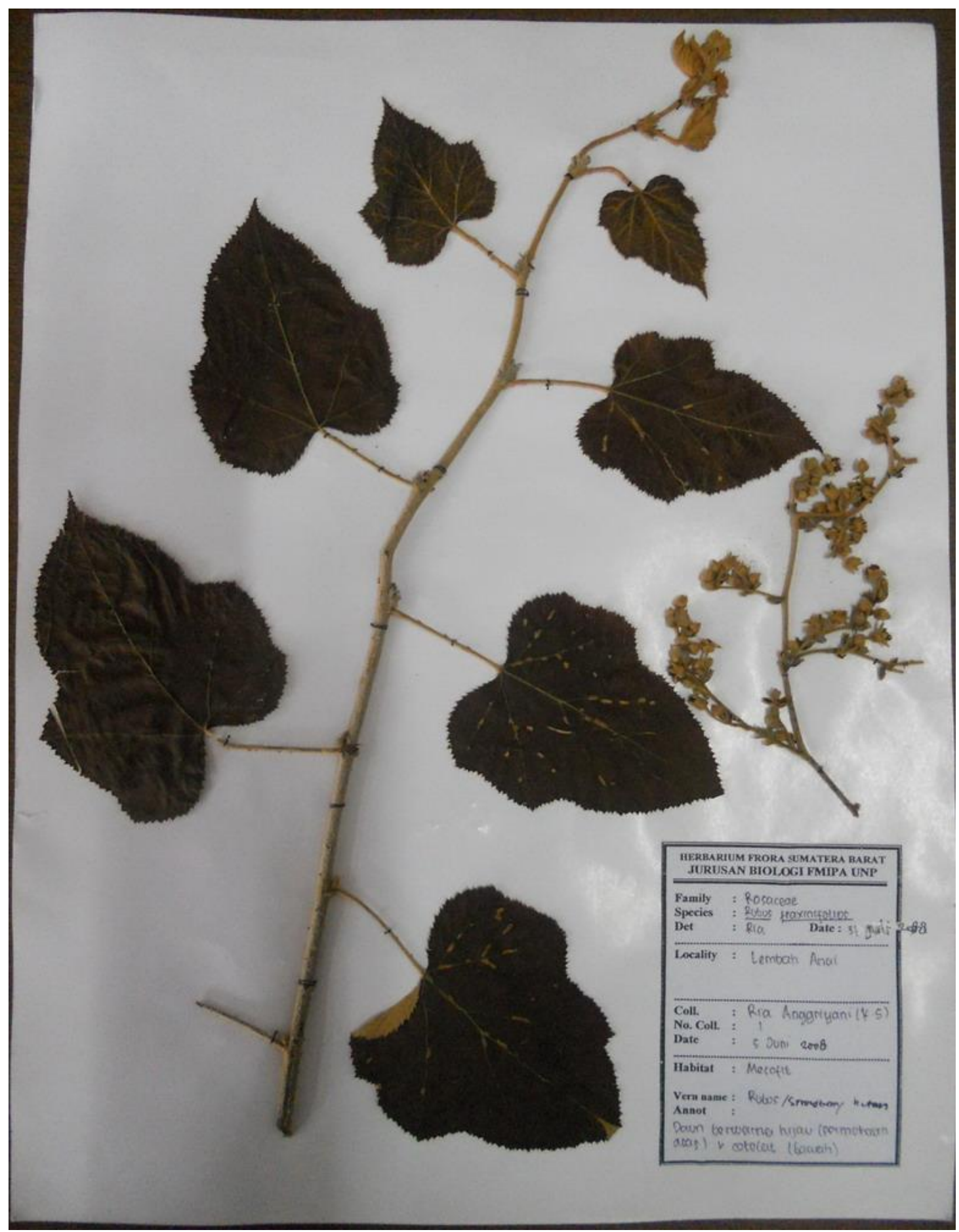

Gambar 1: Contoh Herbarium 

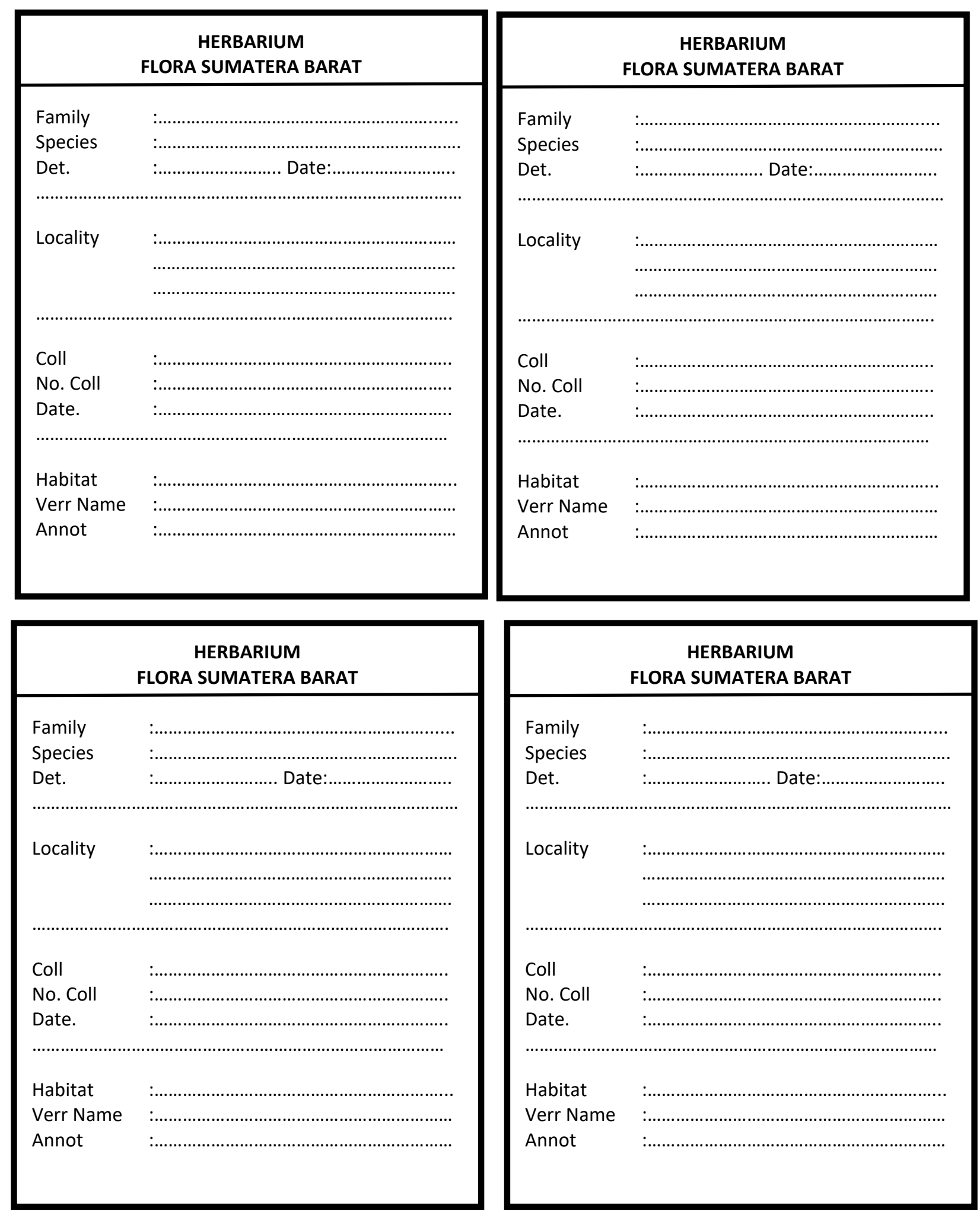

Gambar 2. Contoh labeh herbarium 


\section{DAFTAR PUSTAKA}

Des, M. 2007. Taksonomi Tumbuhan Tinggi. Program Studi Pendidikan Biologi Jurusan Biologi FMIPA Universitas Negeri Padang, Padang.

Rizki, 2011. Sistematika Tumbuhan. Rios Multicipta: Padang

Rizki, R., Sari, T. M., \& Sari, D. M. (2017). Ethnobotani Study on Mangrove Forests in Padang City and Pariaman City. Bioscience, 1(2), 87-91.

Rugayah, R. A., Windadri, F. I., \& Hidayat, A. (2004). Pengumpulan data taksonomi. Da-lam: Rugayah, Widjaja EA \& Praptiwi (eds.). Pedoman Pengumpulan Data Keanekaragaman Flora. Bogor: Puslit-LIPI, 5-42. 